\title{
Cognitive, behavioral, social, and cultural characteristics of the city and urban design
}

\author{
Mahyar Arefi ${ }^{1} \cdot$ Noha Nasser $^{2}$
}

Accepted: 16 August 2021 / Published online: 30 August 2021

(c) The Author(s), under exclusive licence to Springer Nature Limited 2021

Physical determinism characterizes one of the most enduring disputed concepts facing urban designers and planners to date. According to sociologist Herbeter Gans (1968), for example, that the physical conditions of the built environment affect social behavior seems overrated. Dumbing down other indicators such as culture, human behavior, etc., has meant that planners have typically ascribed rigor and power to the built environment based on density, block size, mixeduse, etc. Within this debate, urban design as a discipline has experienced serious ebbs and flows over the last half a century.

This issue of the journal explores different sides of the debate; the papers explore the nexus between urban design on one hand, and the physical or environmental as well as cognitive, social, behavioral and/or cultural aspects of the built environment.

The first article, "More than 'urban character': an introduction to the concept of fengmao and fengmao-led planning and design in China," Deljana Lossifova argues that the concept of Fengmao (urban character) has found widespread application in urban design in China over the last four decades. Used as a measure for evaluating cultural heritage, this article links its role in enhancing China's urban development characteristics beyond what is commonly understood. While authors acknowledge and convey its practical utility in the local cultural development, they identify its inefficiency in engaging the local stakeholders in the development process as well as promoting for a more active role factoring in the ecological and ecosystem considerations.

Like the previous article, in "Scale or size? An analysis of the factors that affect building density: evidence from high-density central urban zones in Asia," Junyan Yang too focuses on the Asian culture. But unlike the previous

\footnotetext{
Mahyar Arefi

mahyararefi@gmail.com

Jundi-Shapur University of Technology, Dezful, Iran

2 Cardiff University, Cardiff, UK
}

research though, where a cultural concept failed to incorporate the importance of ecological or social factors in sustainable development, this article sheds some light on this relationship win the broader context of 17 Asian cities. The author explores the relationships between the block size and building density, where smaller block sizes correlate with higher building densities. More specifically, the author finds the nexus between small block size and higher density as an outlet for achieving sustainable development and compact cities.

Similar to the first article that explores the role of a particular Chinese concept (i.e., Fengmao) in engaging the local stakeholders in urban design, "Nathan Phillips Square: Mediating Intercultural Encounter through Urban Design" by Jonathan Daly examines the interface between the public space and multi-culturalism in Toronto. Interestingly enough, the paper critiques the failings of a public space's symbolic capital inducing social/cultural diversity in the city. So, in more ways than one, these two articles report similar findings in two different North American and Chinese contexts.

Justin Hollander's article entitled "Cognitive responses to urban environments: behavioral responses in lab and field conditions," explores another way in which the built environment and its social, behavioral, and cognitive dimensions affect each other. The author shows the urban design implications of these variables by unfolding four architectural principles.

The last article in this issue, "Urban design frameworks, user activities and public tendencies in Brisbane's urban squares," Rajjan Chitrakar addresses the ways in which urban design frameworks encourage or discourage social activity in public squares. The conclusion highlights the importance of not getting solely caught up with providing a "respite" from unfavorable conditions (i.e., weather). Instead, they bring attention back to simple but profound observations including seeing and being seen, where 
watching other people potentially begets social interaction within the context of Brisbane.

\section{Reference}

Gans, Herbert J. 1968. Urban vitality and the fallacy of physical determinism. In People, plans and policies, ed. H.J. Gans, 33-43. New York: Columbia University Press.
Publisher's Note Springer Nature remains neutral with regard to jurisdictional claims in published maps and institutional affiliations. 